\begin{tabular}{l|l}
\hline SISTEMA \\
ELETRONICO \\
DE REVISTAS \\
SER I UfPR
\end{tabular}

\title{
Mídia brasileira e mudanças climáticas: uma análise sobre tendências da cobertura jornalística, abordagens e critérios de noticiabilidade
}

\section{Brazilian Media and Climate Change: Analysis of Media Coverage Trends, Approaches and Criteria of Newsworthiness}

\author{
Caroline de Araújo RODAS ${ }^{1}$, Gabriela Marques DI GIULIO ${ }^{1 *}$ \\ ${ }^{1}$ Faculdade de Saúde Pública, Universidade de São Paulo (USP), São Paulo, SP, Brasil. \\ *E-mail de contato: ggiulio@usp.br
}

Artigo recebido em 25 de outubro de 2016, versão final aceita em 9 de fevereiro de 2017.

RESUMO: A mídia, com seu papel de revigorar a esfera pública e criar um fórum para o discurso público, tem sido importante para a compreensão pública das mudanças climáticas, incluindo suas incertezas, controvérsias, riscos e ameaças, bem como as projeções futuras e as possibilidades de enfrentamento. Ao oferecer ao público formas simbólicas de representação da relação dos indivíduos com o fenômeno, a mídia tem a responsabilidade de tentar representar as questões complexas que cercam as mudanças climáticas, relacionando-as às experiências da vida moderna. Compreender essa divulgação midiática e suas características é um importante desafio colocado aos pesquisadores que se debruçam sobre a tríade ciência, comunicação e sociedade. Este artigo busca trazer contribuições para esse campo analítico, particularmente para uma lacuna que ainda existe em estudos sobre mudanças climáticas e cobertura midiática no Brasil, a partir da análise e da discussão de resultados de uma pesquisa que teve os seguintes objetivos: (i) compreender a divulgação de questões relacionadas às mudanças climáticas e à energia, a partir da análise de notícias publicadas em um jornal de grande circulação no Brasil, tendo como recorte temporal o período 2000 a 2014; e (ii) compreender percepções dos jornalistas sobre a cobertura jornalística feita acerca desses temas, a partir da análise de conteúdo das entrevistas realizadas com profissionais que cobrem esses assuntos em suas rotinas. Neste artigo, os resultados são apresentados e discutidos à luz de três argumentos analíticos: (i) tendência a uma cobertura jornalística mais centrada em eventos e acontecimentos pontuais; (ii) alterações na abordagem da cobertura sobre mudanças climáticas ao longo dos anos; (iii) adoção de critérios de noticiabilidade na seleção das informações divulgadas e na cobertura sobre mudanças climáticas, incluindo senso de oportunidade, interesse (pelo) humano e conflito.

Palavras-chave: mídia; mudanças climáticas e energia; cobertura midiática; critérios de noticiabilidade; Brasil.

ABSTRACT: The media have an important role in invigorating the public sphere and creating a forum for public discourse. This is especially critical for climate change and the public understanding of this phenomenon, including its uncertainties, controversies, risks and threats as well as future projections and coping possibilities. The media 
offer to the individuals symbolic forms of representing their relations with the phenomenon, and have the responsibility to represent complex issues related to climate change, seeking to connect them to the experiences of modern life. Understanding how the media have covered and diffused these issues is a big challenge for researchers who work on the triad science - communication - society. This paper seeks to contribute to this analytical field and filling the gap in terms of Brazilian studies focused on climate change and coverage, presenting and discussing results of a study conducted between 2014 and 2016, which aimed: (i) to understand the coverage media of issues related to climate change and energy throughout an analyses of news published between 2000 and 2014 in a large national Brazilian newspaper; (ii) to understand journalists' perceptions of media coverage on climate change through content analysis of interviews with Brazilian professionals who cover these issues. Results are presented and discussed considering three arguments: (i) tendency for an event-centred coverage reporting; (ii) change in the coverage trends of climate change along the years; (iii) adoption of criteria of newsworthiness to select information and cover climate change, including sense of opportunity, interest for human and conflict.

Keywords: media; climate change and energy; coverage; criteria of newsworthiness; Brazil.

\section{Introdução}

Mudanças climáticas. Aquecimento global. Nos últimos anos, esses termos ganham visibilidade nos discursos científicos e políticos, são representados pela mídia a partir de diferentes enquadramentos e estão cada vez mais presentes nas narrativas individuais. Apresentados quase sempre como sinônimos, embora as mudanças climáticas envolvam muito mais do que o aquecimento do planeta, como reconhecem Weber e Stern (2011), esses termos têm ganhado evidência na opinião pública, especialmente a partir da divulgação do primeiro relatório de avaliação assinado pelos cientistas reunidos em torno do Painel Intergovernamental sobre Mudanças Climáticas (IPCC), em 1990.

Naquele momento, o relatório apresentou o consenso entre os cientistas sobre o fato de que as emissões provocadas pelas atividades humanas aumentavam substancialmente as concentrações atmosféricas de gases de efeito estufa (GEE) e, por isso, resultavam em um aquecimento adicional da superfície da Terra. Nessa perspectiva, o relatório apontou a necessidade de desaceleração do processo de aquecimento global, com o emprego de um esforço político e econômico mundial urgente por meio de uma convenção-quadro sobre mudanças climáticas que agisse tanto na contenção e na redução de emissões desses poluentes, com a adoção de medidas de mitigação, como na implementação de estratégias de adaptação (Giesbrecht et al., 2015).

Em sua quinta edição, os relatórios do IPCC continuam a sinalizar a necessidade de reduzir significativamente as emissões globais de GEE na tentativa de conter o aumento da temperatura média global em $2{ }^{\circ} \mathrm{C}$ em relação à era pré-industrial, bem como evidenciam a urgência de estratégias e escolhas que reduzam as mudanças climáticas e seus impactos e busquem sinergias com ações que asseguram uma gestão de risco eficaz e medidas adaptativas (Denton et al., 2014). Recentemente, o relatório The truth about climate change, divulgado em setembro de 2016, ${ }^{1}$ apontou que em 2015 a temperatura média do planeta já superou a marca de $1^{\circ} \mathrm{C}$ acima dos níveis registrados na época pré-industrial.

\footnotetext{
1 Disponível em: <http://agencia.fapesp.br/acordo_de_paris_e_insuficiente_para_frear_o_aquecimento_global_diz_relatorio/24052/http:// feu-us.org/the-report/>. Acesso em: 03 out. 2016.
} 
Essas constatações levaram os 195 países signatários da Convenção-Quadro das Nações Unidas sobre Mudança do Clima (UNFCC) a firmarem um acordo climático global durante a $21^{\mathrm{a}}$ Conferência das Partes (COP-21), realizada em 2015, em Paris, estabelecendo cada um deles sua Pretendida Contribuição Nacionalmente Determinada (Intended Nationally Determined Contribution - INDC). Desde 2016, o mundo tem assistido aos governantes ratificarem o Acordo de Paris, como já o fizeram EUA, China e Brasil. No caso brasileiro, os objetivos contidos no tratado passaram a ser lei no país após a sanção presidencial, em setembro daquele ano.

Ainda que a reação ao tema das mudanças climáticas venha ganhando adensamento político, tanto em nível global como em escala mais local, esse fenômeno é bastante complexo e desafiador porque traz reais questionamentos acerca do status quo econômico e político (Leite, 2015) e coloca a ciência, ao mesmo tempo, como uma entidade que lhe confere existência e visibilidade, e pela qual são apresentados tendências, cenários, impactos, riscos e estratégias de enfrentamento. A mídia, com seu papel de revigorar a esfera pública e com a oportunidade de criar um fórum para o discurso público (Hansen, 2000; Szerzynski \& Toogood, 2000), inclusive sobre as mudanças climáticas, tem sido importante para a compreensão pública dessas tendências, consequências e medidas apresentadas (Moser, 2014; Ford \& King, 2015; Happer \& Pilo, 2015). Argumentamos que, por se tratar de questões complexas, caracterizadas por riscos, controvérsias e ambiguidades, à mídia cabe o importante papel de mediador (Anderson, 2009; Carvalho, 2010; Brüggemann \& Engesser, 2014; Loose \& Carvalho, 2015; Engesser \& Brüggemann, 2016), oferecendo ao público formas simbólicas de representação da relação dos indivíduos com o fenômeno. A mídia tem, assim, a responsabilidade de tentar representar essas questões para o público relacionando-as às experiências da vida moderna (Allan et al., 2000), atribuindo significado e legitimidade ao problema (Zamith et al., 2012; Di Giulio et al., 2015).

Entre as questões climáticas relacionadas a tendências e consequências, os estudos realizados e reproduzidos nas notícias jornalísticas apontam alterações na distribuição, intensidade e frequência geográfica dos riscos relacionados às condições meteorológicas (IPCC, 2013), ameaçando exceder as capacidades dos países, especialmente os mais pobres, de absorver perdas e recuperar-se dos impactos e desastres (Climate and Development Knowledge Network, 2012). No caso brasileiro, particularmente, o Primeiro Relatório de Avaliação Nacional do Painel Brasileiro de Mudanças Climáticas (PBMC, 2013), que reúne os principais resultados científicos consensuais das projeções regionalizadas de clima para os diferentes biomas do Brasil, indica que mudanças importantes no clima devem acontecer ainda neste século. Essas mudanças devem trazer impactos sociais e econômicos sobre a produção de alimentos, commodities e energia (Darela-Filho et al., 2016) e um conjunto de novos riscos e ameaças que podem agravar as situações de risco já existentes, particularmente em áreas urbanas (Nobre et al., 2010; Marengo, 2015).

Entre as medidas a serem tomadas apresentadas pela ciência e representadas publicamente pela mídia, ganham destaque aquelas focadas na mitigação, que apontam a necessidade de diminuir a emissão de $\mathrm{GEE}$, em particular $\mathrm{CO}_{2}$ e $\mathrm{CH}_{4}$, resultantes da queima de matéria fóssil (como o petróleo), e de adotar um sistema energético mais limpo (Stern, 2006; 2014; IPCC, 2007; 2013). No caso brasileiro, a mitigação também tem ganhado mais visibilidade do que a adaptação no debate climático (IPEA, 2011; Darela-Filho et al., 2016; 
Di Giulio et al., 2016a; 2016b). Entre as metas propostas pelo Brasil, no âmbito do Acordo de Paris, por exemplo, estão a redução de emissões em 37\% (GWP-100) em 2025, em relação aos níveis de 2005 , e a possibilidade de redução de até $43 \%$ (GWP-100) em 2030. Para isso, o Brasil sinaliza que pretende aumentar o uso sustentável de energias renováveis na sua matriz energética e investir em ações no setor de uso da terra, florestas e pecuária, com desmatamento ilegal zero na região amazônica e medidas de restauração e reflorestamento em todo o território (Itamaraty, 2015).

Compreender como a mídia tem divulgado tais questões associadas às mudanças climáticas constitui-se como importante desafio colocado aos pesquisadores que se debruçam sobre a tríade ciência, comunicação e sociedade. Nessa perspectiva, este artigo busca trazer contribuições para esse campo analítico, preenchendo particularmente uma lacuna que ainda existe em estudos sobre mudanças climáticas e cobertura midiática em outros países, incluindo o Brasil, para além de Estados Unidos, Europa, Austrália, Índia e Nova Zelândia (Zamith et al., 2012), a partir da análise e discussão de resultados de uma pesquisa desenvolvida entre os anos de 2014 e 2016, cujos objetivos foram: (i) compreender a divulgação de questões relacionadas às mudanças climáticas e à energia, a partir da análise de notícias publicadas em um jornal de grande circulação no Brasil, tendo como recorte temporal o período de 2000 a 2014; e (ii) compreender percepções dos jornalistas sobre a cobertura jornalística feita acerca desses temas, a partir da análise de conteúdo das entrevistas realizadas com profissionais que cobrem esses assuntos.

Neste artigo, fruto de um recorte da pesquisa desenvolvida pelas autoras, esses resultados são discutidos à luz de três argumentos analíticos: (i) tendência a uma cobertura mais centrada em eventos e acontecimentos pontuais; (ii) mudança na abordagem da cobertura sobre mudanças climáticas ao longo dos anos; (iii) adoção de critérios de noticiabilidade na seleção das informações divulgadas e na cobertura sobre mudanças climáticas, incluindo senso de oportunidade, interesse (pelo) humano e conflito, comuns na cobertura de questões ambientais em geral.

Tais argumentos servem também como estrutura deste artigo, que está dividido em seis seções, para além desta Introdução. Nas próximas seções, o artigo apresenta apontamentos teóricos sobre mídia e mudanças climáticas e os procedimentos metodológicos da pesquisa; parte, então, para as três seções analíticas, com os resultados do estudo discutidos à luz da literatura revisada, e, finalmente, apresenta as conclusões das autoras.

\section{Apontamentos sobre mídia e mudanças climáticas}

O conhecimento científico, os avanços tecnológicos e a questão ambiental tal como aparecem na mídia ajudam a constituir o modo como entendemos diversos problemas contemporâneos, que caracterizam a alta modernidade, ou modernidade reflexiva (Giddens, 1999; Beck, 2011), como as mudanças climáticas. Desde uma perspectiva construcionista, é possível argumentar que, na construção de um problema ambiental, como as mudanças climáticas, diversos fatores estão presentes: (1) ter autoridade científica e validade para as reivindicações postuladas; (2) contar com divulgadores científicos, que transformam um objeto de estudo considerado fascinante e enigmático em uma reivindicação proativa ambientalmente; (3) receber atenção da mídia, que mostra esse objeto como algo real e importante; (4) ganhar dramaticidade em termos simbólicos e vi- 
suais; (5) haver incentivos econômicos visíveis para a tomada de decisão sobre aquele objeto (neste caso, o problema ambiental); (6) garantir que haja um patrocinador institucional que garanta legitimidade à questão e sua continuidade na agenda (Hannigan, 2006). Nesse rol de fatores, a mídia ganha destaque, já que, ao lado da ciência, das leis e da política, ela define, seleciona e dá visibilidade e legitimidade a um problema ambiental - ou a determinado risco, como argumenta Beck (2011).

Compreendendo que os meios de comunicação têm a capacidade de agendar os temas que são objeto de debate público e que, quanto maior é a ênfase dada pelos meios sobre um tema e quanto mais contínua é essa abordagem, maior é a importância que o público tende a lhe atribuir em sua agenda (McCombs, 2004; McCombs \& Shaw, 2012), argumentamos que, embora a construção última de sentido dependa do receptor, a comunicação jornalística é um dos agentes que intervêm no processo de construção social da realidade (Sousa, 1999), na conformação da agenda ambiental (Hannigan, 2006) e na amplificação ou atenuação das percepções e preocupações do público sobre determinado fato e evento (Flynn et al., 2001; Pidgeon et al., 2003; Kasperson et al., 2005; Di Giulio et al., 2008; Di Giulio, 2012).

Particularmente sobre as mudanças climáticas, a mídia desempenha papel-chave na construção das percepções e agendas públicas sobre o fenômeno (Anderson, 2009). Compreender as dinâmicas desses processos tem sido um eixo importante nos estudos conduzidos por pesquisadores das Ciências Sociais e da Comunicação, particularmente a partir da década de 1990 (Anderson, 2009). Parte das pesquisas tem se centrado nas características das coberturas jornalísticas e nas representações midiáticas sobre o fenômeno (McComas \& Shanahan, 1999; Carvalho \& Burgess, 2005; Loose \&
Carvalho, 2015). Outros estudos são mais focados nos discursos midiáticos (Carvalho, 2007; 2010) e direcionados às representações da ciência do clima e no processo de mediação da informação científica (Engesser \& Brüggemann, 2016). Há ainda aqueles que buscam análises comparativas sobre a cobertura midiática das mudanças climáticas em diferentes países (Barkemeyer et al., 2017, por exemplo).

De modo geral, é possível observar que a questão climática ganhou maior espaço na mídia a partir de 1997, com a elaboração do Protocolo de Quioto, tratado internacional lançado naquele ano que propôs aos países desenvolvidos signatários um calendário para a diminuição da emissão de GEE. Os embates em torno do conteúdo e da ratificação do Protocolo de Quioto entre os diversos países adensaram as discussões políticas e acadêmicas sobre as mudanças climáticas (Giesbrecht et al., 2015), refletindo em uma maior atenção da mídia sobre o assunto (Anderson, 2009).

A divulgação dos relatórios do IPCC, a realização de eventos internacionais relevantes na conformação de uma governança internacional das mudanças climáticas, a atuação de celebridades como porta-vozes das questões do clima e as recentes produções audiovisuais sobre o fenômeno também têm sido apontadas por alguns estudiosos como eventos detonadores ou com forte peso para a cobertura midiática sobre o fenômeno (Lowe et al., 2006; Anderson, 2009; ANDI, 2010; Artaxo Netto, 2013; Boykoff \& Yulsman, 2013; Ford \& King, 2015), conectada fortemente às decisões políticas tomadas (Anderson, 2009).

Alguns desses estudos buscam aplicar a ideia de ciclos de atenção a um assunto (issue attention cycle) para explicar a oscilação da atenção e do foco da mídia e, consequentemente, o aumento e a diminuição de notícias divulgadas durante um período (McComas \& Shanahan, 1999; Anderson, 
2009). Nessa perspectiva, a questão climática, como a ambiental como um todo, é entendida como suscetível às oscilações (ups and downs) em termos de interesse público (McComas \& Shanahan, 1999). À medida que diminuem seu valor dramático ou de entretenimento, afetam menos pessoas e não despertam mais interesses em termos de poder, ao mesmo tempo em que envolvem grandes perturbações e custos (Anderson, 2009), as notícias ambientais tendem a perder espaço e atenção pública para outras questões consideradas mais interessantes ou pressionadoras (McComas \& Shanahan, 1999).

Essa abordagem, ainda que explicativa, é vista como linear e inflexível, especialmente ao olhar as interfaces entre mídia e mudanças climáticas. A compreensão de como as rotinas dos jornalistas, suas ideologias e relações com as fontes impactam a cobertura, as formas como a organização da qual o veículo de comunicação faz parte delineia o enfoque das notícias, bem como determinados significados e discursos têm sido refletidos e reforçados na cobertura midiática são vieses desafiadores para pesquisas (Anderson, 2009).

Nessa perspectiva, a literatura destaca os critérios que pesam na seleção dos fatos e na produção de notícias. Dentre os chamados critérios de noticiabilidade, ganham destaque os valores-notícia, ou seja, aqueles atributos subjetivos que, embora muitos jornalistas não saibam explicar o motivo, influenciam no momento de escolher um fato em detrimento de outro (Anderson, 1997; Miller \& Riechert, 2000; Bonanno, 2015; Bednarek, 2016). Esses atributos apresentam aspectos cognitivos, sociais, discursivos e materiais (Bednarek, 2016) e não apenas decidem se um fato será ou não noticiado, como definem quanta ênfase será dada a ele (Miller \& Riechert, 2000). As questões ambientais, como as mudanças climáticas, não são, por si sós, fatos que reúnam alguns dos mais comuns valores de notícia, como consequências, proximidade, proeminência e interesse humano. Outros critérios parecem ser mais preponderantes para que fatos que envolvam riscos e questões ambientais sejam noticiados, como o envolvimento de algum tipo de conflito entre tomadores de decisão, governantes, stakeholders (Miller \& Riechert, 2000) e a ocorrência/realização de algum evento específico (Hannigan, 2006), o que colaboraria para coberturas mais centradas em eventos e acontecimentos pontuais (event-centred coverage reporting).

Além desses, Hannigan (2006) argumenta que, para ganhar proeminência, um problema ambiental deve ser moldado em consonância com conceitos culturais existentes, deve ser articulado com as agendas política e científica, ter relação com o presente (e menos com o futuro) e ter uma agenda de ação atrelada ao nível internacional ou ao nível de uma comunidade local.

Anderson (1997) observa ainda que, entre os fatores que moldam as notícias jornalísticas, estão a frequência, a amplitude do nível de amplificação de um evento, a relevância em termos de proximidade cultural e a relação com a vida diária, a consonância com ideias preconcebidas sobre um grupo social ou uma nação, a raridade, a continuidade e o poder competitivo. Na lógica da comunicação de massa, na visão de Sturloni (2006), a relevância de um risco ambiental - por exemplo, as mudanças climáticas - depende também dos fatores legais de noticiabilidade do evento: pluralidade de elementos de natureza sociocultural (proximidade, violação de normas de conduta), narrativa (presença de vítima identificada, atribuição de culpa, existência de um conflito) e técnica (disponibilidade de imaginação, inserção em um contexto preexistente).

Ainda que a cobertura midiática sobre as mudanças climáticas já contabilize pelo menos quase três décadas, considerando os estudos que têm sido 
desenvolvidos sobre mídia e clima desde os anos 1990, análises mais recentes continuam a evidenciar maior ênfase aos acordos globais e a medidas governamentais e dificuldades em aproximar a questão climática do público (O’Neill \& Nicholson-Cole, 2009; Loose \& Carvalho, 2015).

Nesse sentido, por exemplo, Aguiar e Schaun (2011) discutem como as notícias sobre as catástrofes ecológicas globais, como as mudanças climáticas, passaram a ter amplo destaque na mídia e demonstram de que modo esses discursos jornalísticos vinculam a crise do meio ambiente a uma heurística do medo, na qual o signo da negatividade esvazia a possibilidade da ação política. Bueno (2009) argumenta que a despolitização da cobertura jornalística tenta estigmatizar os que declaradamente apoiam a causa ambiental (considerados radicais), acomodando-se ao discurso que se vale de informações, dados e estatísticas supostamente acima de qualquer suspeita para fazer prevalecer uma perspectiva comprometida com interesses econômico-financeiros. Essa cobertura, segundo o autor, tenta consolidar o caráter pretensamente neutro da ciência e da tecnologia, o que é nocivo e contraproducente quando se examina a temática ambiental.

\section{Procedimentos metodológicos}

A pesquisa realizada no período de 2014 a 2016 privilegiou uma abordagem qualiquantitativa e foi dividida em dois momentos. Inicialmente, foi realizada uma pesquisa documental no acervo on-line do jornal de circulação nacional Folha de S.Paulo, tendo como recorte temporal o período de janeiro de 2000 a outubro de 2014. Esse intervalo possibilitou contemplar importantes eventos/marcos que tiveram como enfoque questões ambientais, incluindo as mudanças climáticas e questões energéticas, como as duas conferências internacionais sobre meio ambiente - a Rio+10 em Joanesburgo, África do Sul, em 2002, e a Rio+20, no Rio de Janeiro, em 2012 -, Conferências do Clima (COP) e a divulgação de relatórios do IPCC. A opção por analisar notícias divulgadas no acervo on-line do jornal Folha de S.Paulo é embasada também nos resultados de uma pesquisa realizada pela Secretaria de Comunicação Social do governo federal brasileiro, em 2014, intitulada "Pesquisa Brasileira de Mídia", que revelou que o público consultado tem maior confiança em notícias divulgadas por jornais impressos em relação a notícias veiculadas em outros meios, como rádio e TV. Quanto ao veículo escolhido para análise, cabe ressaltar que a Folha de S. Paulo é um dos jornais mais lidos e acessados pelo público brasileiro. Em 2013, ocupava a segunda posição no ranking dos jornais, segundo dados do Instituto Verificador de Circulação (IVC, $2013^{2}$ ). Além disso, esse veículo - quando comparado com outros concorrentes também de circulação nacional - apresenta mecanismo eficiente de busca para pesquisa on-line, o que facilitou sua seleção.

$\mathrm{Na}$ busca das notícias, o recorte adotado centrou-se na conexão entre mudanças climáticas, poluição e energia (Stern, 2006; 2014; IPCC, 2007; 2013), partindo de um entendimento e do discurso dos especialistas brasileiros de que a principal causa das mudanças climáticas é a emissão excessiva de GEE na atmosfera, em particular $\mathrm{CO}_{2}$ e $\mathrm{CH}_{4}$, devido principalmente à queima de combustíveis fósseis provocada por ações humanas, e de que, entre as soluções propostas, articuladas a um conjunto de

\footnotetext{
${ }^{2}$ Consultar: http://www.meioemensagem.com.br/home/midia/2014/01/27/circulacao-de-jornais-cai-de-1-9-em-2013.html. Acesso em: 03 out. 2016 .
} 
políticas públicas, ganha destaque a necessidade de adoção de um sistema energético mais limpo, na perspectiva de fomentar e acelerar a transição para uma economia de baixo carbono (Baran et al., 2015).

Com o auxílio de palavras-chave que resultaram em uma expressão de busca - ("mudanças climáticas" OR "mudança climática" OR "alteração climática" OR "alterações climáticas" OR "aquecimento global" OR clima) AND polu* AND energ* - foram encontrados 502 resultados. Desse número, 97 foram descartados por fugirem do escopo da pesquisa, não tratando especificamente de mudanças climáticas, ou por se tratar de publicidade, com propaganda de algum produto, tema irrelevante para o estudo. Foi observada ainda a ocorrência de notícias duplicadas, as quais também foram excluídas. Assim, a pesquisa documental centrou-se na análise de 405 peças jornalísticas.

Foi realizado o download desses textos e iniciado o processo de análise quantitativa e qualitativa para classificar o material quanto ao tipo de fonte citada e à editoria em que a notícia foi publicada, bem como observar enfoques gerais e específicos dos textos encontrados, tendo em vista os dois temas centrais da pesquisa: mudanças climáticas e questões energéticas). A análise também se centrou em compreender possíveis mudanças de posicionamento do governo brasileiro sobre essas questões ao longo dos 14 anos, a partir da perspectiva divulgada no jornal brasileiro. Parte dos resultados obtidos nessa primeira análise é apresentada e discutida no presente texto, considerando o enfoque e o escopo deste artigo.

A segunda parte da pesquisa consistiu na realização de entrevistas, entre 2015 e 2016, com jornalistas especializados na cobertura de questões ambientais, enfocando mudanças climáticas e questões energéticas. Para a seleção dos jornalistas entrevistados foram considerados dois critérios fundamentais: (i) atuação na cobertura desses temas (sendo considerados, assim, jornalistas especializados nessa temática); (ii) atuação em diferentes veículos de comunicação, no âmbito regional (São Paulo) e nacional. Foram selecionados e entrevistados dois jornalistas do jornal Folha de S.Paulo, um jornalista do jornal $O$ Estado de S. Paulo, um jornalista da rádio $\mathrm{CBN}$ e um jornalista da revista Pesquisa Fapesp. ${ }^{3}$ Outros jornalistas que atuam com esses temas nesses e em outros veículos foram selecionados, contudo não atenderam à solicitação de realização de entrevistas. A amostra restrita de entrevistados não inviabilizou a pesquisa, considerando que o enfoque qualitativo do estudo buscou, a partir das entrevistas semiestruturadas em formato livre, compreender, na perspectiva desses profissionais, suas percepções sobre a cobertura midiática e as tendências que se apresentam. Para a realização das entrevistas, os jornalistas foram contatados através de e-mail e contato telefônico, e os encontros foram agendados entre os meses de novembro de 2015 e fevereiro de 2016, considerando a disponibilidade e a facilidade de local sugerido pelos profissionais (dois deles optaram por conceder a entrevista na Faculdade de Saúde Pública da USP, onde a pesquisa foi realizada, e um dos profissionais, no seu local de trabalho). Um dos jornalistas optou por conceder a entrevista via Skype, e outro pediu que o roteiro fosse encaminhado por e-mail, optando por responder às questões por escrito.

A opção pelas entrevistas semiestruturadas em formato livre partiu da posição ontológica das

\footnotetext{
${ }^{3}$ Identificados neste artigo como: Jornalista 1 - Folha de S. Paulo; Jornalista 2 - O Estado de S. Paulo; Jornalista 3 - CBN; Jornalista 4 - Folha de S. Paulo; Jornalista 5 - Pesquisa Fapesp.
} 
pesquisas, reconhecendo que o conhecimento dos indivíduos entrevistados, suas visões, compreensões, interpretações, experiências e interações são propriedades significativas da realidade social cuja pesquisa busca explorar. Além disso, esse formato de entrevista permite tomar depoimentos como fonte de investigação, podendo, assim, como argumenta Duarte (2004), extrair aquilo que é subjetivo e pessoal nos relatos, facilitando, posteriormente, conexões com a dimensão coletiva e a lógica das relações que se estabelecem no interior dos grupos sociais dos quais o entrevistado participa.

$\mathrm{O}$ roteiro das entrevistas foi norteado pelas análises de dados que emergiram das notícias dos jornais e incluiu questões sobre interesse e opção dos jornalistas pela cobertura de temas ambientais, avaliação da cobertura sobre os temas tratados no Brasil e internacionalmente, fontes de informação consultadas, avaliação sobre o posicionamento do Brasil (governo) em relação às mudanças climáticas e a questões energéticas no período de 2000 a 2014, cobertura caracterizada por ser centrada em eventos, mudança na abordagem dos temas, critérios de noticiabilidade na escolha e nos enquadramentos e impactos das notícias. O conjunto de informações recolhidas foi analisado a partir da técnica identificada como análise temática, que prevê a organização dessas informações em eixos temáticos, articulados aos objetivos da pesquisa (Duarte, 2004). Nessa técnica, o cruzamento das falas dos participantes pode ser realizado pela articulação dos conteúdos dos diferentes eixos.

Neste artigo, especificamente, são apresentadas e discutidas as percepções dos jornalistas sobre a cobertura realizada, enfoques na cobertura sobre esses temas e critérios de noticiabilidade na seleção das notícias que são divulgadas ao público, a partir dos eixos temáticos definidos.

\section{Cobertura centrada em eventos e acontecimentos pontuais}

A análise das 405 peças jornalísticas acessadas no período de 2000 a 2014 evidencia três momentos em que houve aumento expressivo no número de notícias que enfocavam os temas analisados: 2007, ano que contabilizou 55 notícias divulgadas; 2008, com 61 textos; e 2009, com cem. Comparativamente, de 2000 a 2006, foram contabilizadas apenas 22 notícias. Entre 2010 e outubro de 2014, contabilizaram-se 167 notícias, sinalizando, como apresentado na Figura 1, uma flutuação no volume de cobertura midiática sobre esses temas. Essa redução no número de notícias nos últimos anos do recorte temporal adotado na pesquisa sinaliza certa diminuição de interesse por parte da mídia na cobertura de questões climáticas, o que repercute também na sua visibilidade pública, como reconhecem Happer e Philo (2015).

A análise da expressiva quantidade de notícias entre 2007 e 2009 atribui esse aumento a dois marcos relevantes, no nível internacional, sobre mudanças climáticas registrados no período. Primeiramente, a divulgação do quarto relatório do IPCC, em 2007 (AR-4), que evidenciou que o aquecimento global existia e reconhecia que a principal causa era a emissão de GEE decorrente de atividades humanas. A divulgação desse relatório colocou em pauta a necessidade de tomadas de decisões, especialmente no setor energético (principal responsável pelo aumento de emissão desses gases), e chamou a atenção para investimentos em uma matriz energética renovável.

$\mathrm{O}$ quarto relatório trouxe contribuições dos três grupos de trabalho do IPCC: Working Group I, que reúne estudos a respeito das bases das ciências físicas sobre mudanças climáticas; Working Group II, 


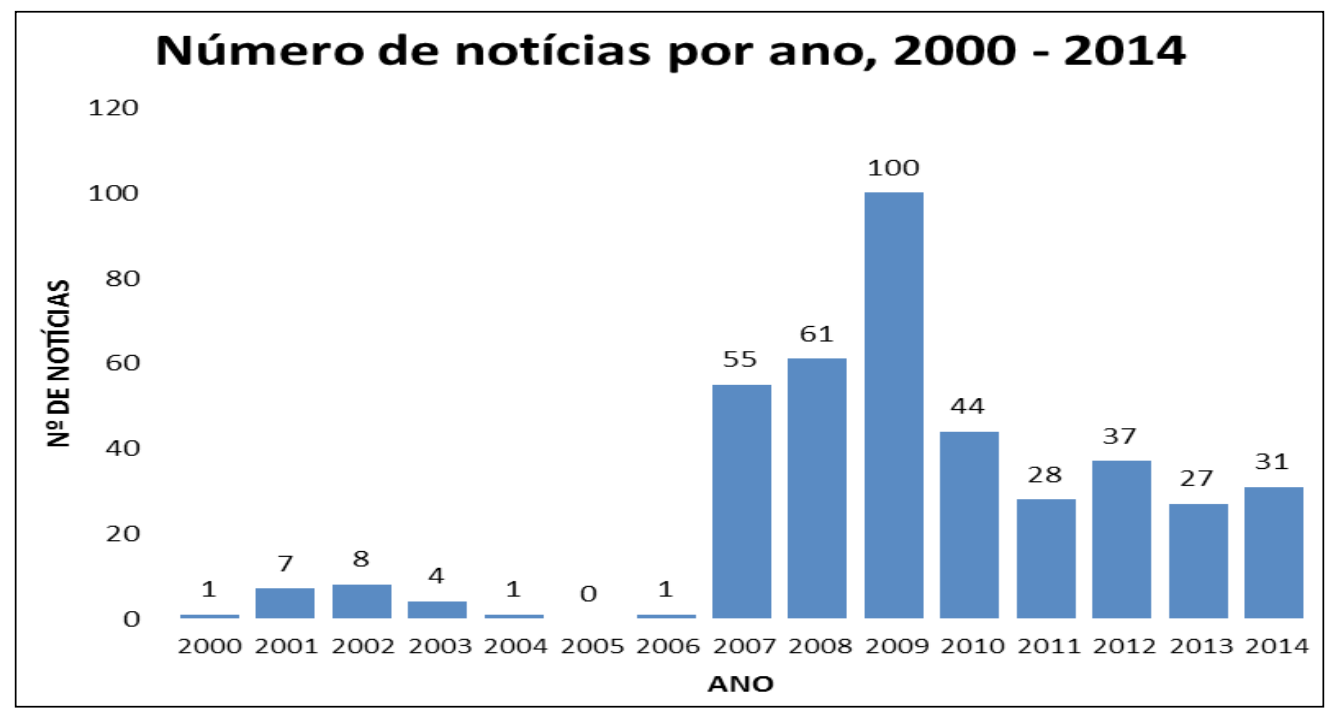

FIGURA 1 - Distribuição das notícias publicadas no jornal Folha de S.Paulo por ano. FONTE: Elaboração própria.

acerca dos impactos, da adaptação e da vulnerabilidade; e Working Group III, que compila dados sobre mitigação. O Relatório-Síntese (Synthesis Report), que compõe o documento divulgado, destacou as mudanças observadas no clima, seus efeitos e as causas dessas alterações; os impactos dos diferentes cenários a curto e longo prazos; opções e respostas de adaptação e mitigação, correlacionando-as com o desenvolvimento sustentável; perspectivas para longo prazo considerando aspectos científicos e socioeconômicos relevantes para adaptação e mitigação; e incertezas que ainda persistem.

Estrategicamente, como observa Artaxo Netto (2013), o IPPC planejou a divulgação desse quarto relatório em quatro etapas, conseguindo, assim, manter o assunto em pauta durante todo o ano de 2007. No Brasil, essa estratégia consolidou a agenda-setting das mudanças climáticas. Cabe ressaltar que, nesse mesmo ano, o IPCC dividiu com Al Gore, ex-vice-presidente dos Estados Unidos, a conquista do Prêmio Nobel da Paz. Al Gore foi agraciado por seus esforços na disseminação de conhecimento sobre as mudanças climáticas, protagonizando o documentário Uma verdade inconveniente. A concessão do Nobel da Paz ao IPCC foi bastante significativa, dando maior visibilidade aos cientistas, que passaram a ocupar espaços editoriais importantes nos veículos de comunicação. Para Artaxo Netto (2013), a divulgação do AR-4 em 2007 representou para o tema, em termos de inserção na mídia, o mais importante desdobramento de projeção que a questão ambiental alcançou desde a Rio-92.

Essa tendência também se repetiu em escala global, como apontam outros estudos revisados por Anderson (2009). A divulgação do AR-4 ainda foi destacada como relevante na análise de notícias focadas em adaptação climática divulgadas em jornais norte-americanos (Ford \& King, 2015). No estudo envolvendo notícias publicadas entre 1993 e 2013 em quatro veículos da América do Norte (The New York Times, The Washington Post, The Globe and Mail e Toronto Star), por exemplo, os autores 
sinalizaram que a divulgação desse relatório do IPCC, em 2007, pesou para o aumento de notícias divulgadas naqueles jornais, particularmente sobre adaptação.

O segundo marco é a realização da Conferência do Clima em Copenhague, Dinamarca, em 2009. A COP15, como ficou conhecida, foi apontada naquele momento como decisiva para as questões ambientais. Nessa conferência, os países signatários da convenção reuniram-se em Copenhague para implementar os objetivos aprovados em 2007, na COP 13, em Bali, no chamado Plano de Ação de Bali. Esse plano colocava como referência para as ações de mitigação o que havia sido proposto no quarto relatório do IPCC, ressaltando a necessária redução das emissões de GEE dos países desenvolvidos de $10 \%$ a $40 \%$ até 2020 .

Como reconhece Moreira (2013), a partir de uma análise sobre a COP15, essa conferência não apenas não alcançou um novo acordo global que substituísse o Protocolo de Quioto, como esperado inicialmente, como ainda evidenciou novas configurações de poder que se colocavam na política internacional do clima, reforçando o papel de alguns países como EUA, China, Índia, Brasil e África do Sul, em detrimento do papel das Nações Unidas nas negociações. O resultado alcançado em Copenhague ficou muito aquém dos objetivos postulados. Uma nova negociação, que fosse vinculante a todos os signatários, não foi concretizada, tendo sido possível somente a assinatura do chamado Acordo de Copenhague, no qual se ratificava o compromisso de limitar o aumento de temperatura em $2^{\circ} \mathrm{C}$ e convocava seus signatários a confirmar suas propostas anunciadas durante a conferência de compromissos unilaterais.

O aumento expressivo das notícias nesse período evidencia que o interesse midiático pelas questões climáticas e energéticas no Brasil segue padrão similar ao que acontece em outros países: tende a crescer durante e após a realização de encontros internacionais e conferências, bem como em momentos de divulgação de importantes documentos, como os relatórios do IPCC, reforçando, assim, uma cobertura centrada em eventos e acontecimentos pontuais (McComas \& Shanahan, 1999; Anderson, 1999; Hannigan, 2006) no tratamento desses temas pela mídia.

Estudo realizado pela Agência de Notícias dos Direitos da Infância (ANDI) e divulgado em 2010 também evidenciou essa característica na cobertura sobre mudanças climáticas no país. O estudo, que teve como objetivo avaliar o comportamento da imprensa brasileira com relação ao tema mudanças climáticas, numa análise comparativa de 50 jornais nos períodos de julho de 2005 a junho de 2007 e julho de 2007 a dezembro de 2008, mostrou a relação entre acontecimentos pontuais e maior cobertura midiática sobre mudanças climáticas. O estudo apontou que a publicação do Relatório Stern em 2006, o lançamento do documentário Uma verdade inconveniente no mesmo ano e a divulgação do Prêmio Nobel da Paz a Al Gore e ao IPCC em 2007 motivaram uma maior atenção da mídia pelo tema, reproduzida em um maior número de notícias entre o final de 2006 e o primeiro semestre de 2007. Esses eventos que marcaram a agenda internacional foram, segundo a pesquisa, suficientemente expressivos para despertar o interesse da imprensa brasileira (ANDI, 2010).

Ford e King (2015) também destacaram as conferências da COP, particularmente a de 2009, e a divulgação de filmes, como o documentário de $\mathrm{Al}$ Gore, como relevantes na cobertura midiática sobre mudanças climáticas nos jornais norte-americanos analisados em seu estudo. Contudo, contrariamente à divulgação do AR-4, os autores chamaram a atenção para o fato de que tais marcos não resultaram 
em maior número de notícias específicas sobre adaptação climática - foco da pesquisa dos autores. Essa tendência a uma cobertura centrada em eventos e acontecimentos pontuais é reconhecida também pelos jornalistas entrevistados no âmbito da pesquisa realizada. A análise das entrevistas mostra que os encontros internacionais, como os realizados pela COP, são entendidos como produtores de notícias que desencadeiam matérias especiais sobre o assunto, porque resultam em discussões políticas e decisões que envolvem, como apontado por um dos jornalistas, "gente importante". Na perspectiva dos jornalistas, esses eventos levam a uma maior divulgação de notícias porque também trazem informações novas e reúnem as fontes necessárias para embasar as notícias.

[...] porque a gente fala que a mídia tem que ser mais preventiva. Tudo bem, eu concordo com isso, mas a sociedade, ainda mais no Brasil, a cultura do brasileiro não é de ser preventiva. O brasileiro quer saber da crise quando ela já está rolando. Então, teve esses dois picos [refere-se aos anos de 2007 e 2009] por causa disso e $100 \%$ de certeza por causa desses eventos internacionais que abriram espaço no jornal (jornalista 1).

Isso é natural da notícia. Um assunto só vira notícia se tiver alguma novidade. Então, são esses relatórios e eventos que causam picos na cobertura, porque mudança climática é um problema que está aí todo dia, é permanente, mas não tem coisas novas. Você não pode publicar matérias falando coisas que já foram ditas muitas vezes ao longo dos anos, né? Então, precisa ter um acontecimento novo para suscitar uma cobertura mais intensa. É natural. Sai um relatório, tem uma conferência e o número de matérias vai aumentar (jornalista 2).

Esses encontros envolvem lideranças internacionais, produtores de informação. Geralmente, quando esses encontros acontecem, relatórios com diversos dados já estão prontos [...] Esses encontros têm muita informa- ção e é natural que a imprensa vá cair matando ali para conseguir alguma coisa nova, declarações, né? [...] O noticiário realmente só vem à tona quando vêm esses grandes encontros e, nesse sentido, eu acho que tem tudo a ver mesmo. Esses encontros internacionais que envolvem grandes potências vão produzir muito mais noticiário do que, por exemplo, agora, que a gente não tem nada acontecendo, entendeu? (jornalista 3 ).

Para os jornalistas, esses eventos e acontecimentos possibilitam chamar a atenção do público para a questão ambiental e abordar o assunto desde uma perspectiva econômica, mostrando os impactos que as mudanças climáticas podem trazer às finanças individuais e aos países. Essa é uma forma, na perspectiva dos entrevistados, de tornar a questão mais relevante para a opinião pública.

Nesses encontros são tomadas decisões políticas que vão orientar ações dos governos e dos países depois, então tem um peso grande, né? E tem uma disputa acirrada para ver o que cada grupo de países vai fazer, como vai se comprometer, porque isso deve ter implicações em crescimento econômico, tem uma questão econômica por trás aí, e são eventos que mobilizam o mundo todo. Então, como o peso disso é grande, é meio óbvio que isso chame atenção, porque o que for decidido ali pode influenciar o caminho que os países vão seguir (jornalista 5).

\section{Mudanças na cobertura sobre mudanças climáticas}

Com base no estudo realizado pela ANDI (2010), que aponta uma mudança de cobertura realizada pela imprensa brasileira sobre mudanças climáticas - de uma abordagem de risco, que tende a enfatizar os impactos climáticos, para uma abordagem mais atenta às estratégias de enfrentamento do problema e de caráter mais preventivo, em consonância com o que acontece também no 
âmbito internacional, destacando a discussão sobre redução de emissões de GEE e incentivo às fontes de energia renovável-, a pesquisa realizada buscou analisar a continuidade dessa tendência de mudança, dentro do escopo da investigação. Para isso, as 405 notícias acessadas na pesquisa documental foram classificadas em três categorias, considerando-se as peças jornalísticas que: 1) abordavam uma relação entre mudanças climáticas e energia, sem mencionar, contudo, fontes energéticas alternativas; 2) abordavam essa relação e mencionavam fontes alternativas de energia; 3 ) não traziam relação entre mudanças climáticas e energia. Tais categorias foram estabelecidas com o objetivo de observar como o debate sobre mudanças climáticas e a necessidade de transição para uma matriz energética baseada em energia renovável (estratégia de enfrentamento) repercutia também nas notícias divulgadas pelo jornal brasileiro - foco da pesquisa realizada.

Os resultados mostram que houve maior expressão de notícias que mencionaram a relação entre mudanças climáticas e energia, citando no corpo do texto algo sobre fontes energéticas alternativas (categoria 2, com 47,4\% das notícias publicadas). Foi também a partir de 2007 que as notícias dessa categoria começaram a ser mais divulgadas, o que pode ser atribuído novamente à divulgação do quarto relatório do IPCC, que chamou a atenção para a emissão de GEE e para a necessidade de transição para uma matriz energética renovável (Rodas \& Di Giulio, no prelo). Na análise de Artaxo Netto (2013), a divulgação do AR-4 influenciou, inclusive, a cobertura midiática feita no Brasil, que deixou de relatar apenas as novidades científicas sobre o tema e passou a chamar a atenção para a intensificação dos eventos meteorológicos extremos, destacando a ausência e/ou a ineficiência de estrutura para lidar com eles.
É importante ressaltar que os anos de 2007 e 2009 também concentraram a maior quantidade de notícias veiculadas que mencionaram o Brasil nos textos apresentados. Das 76 notícias catalogadas na pesquisa (entre 2000 e 2014) que faziam menção e/ou apresentavam alguma relação (direta ou indireta) com o país, 45 circularam nesse período, como discutido em Rodas \& Di Giulio (no prelo). O aumento significativo de notícias divulgadas nesses três anos pode ser atribuído também à mudança de postura do governo brasileiro em relação às mudanças climáticas e a questões energéticas: de uma posição mais conservadora e reticente em relação à necessidade de redução de emissões de GEE para um posicionamento mais proativo. Argumentamos que a mudança na abordagem da cobertura midiática, agora mais centrada nas estratégias de enfrentamento do problema, refletiu também essas alterações da postura brasileira.

Em 2007, por exemplo, a análise das notícias evidenciava que o país parecia não aceitar metas internacionais para a redução de emissões de GEE em países em desenvolvimento. Já no ano seguinte, as notícias não apenas enfocavam a defesa, pelo governo federal, do uso de biocombustíveis em encontros internacionais (particularmente para os países pobres, que buscavam aliar crescimento econômico à inclusão social e ambiental), mas também mostravam o compromisso do país em reduzir o desmatamento na Amazônia. Em 2009, em meio aos preparativos para a Conferência de Copenhague, as notícias revelavam que o Brasil passava a apresentar metas para redução de GEE e continuava a pressionar países ricos para que adotassem medidas de reduções. Contudo, apesar de começar a se comprometer com metas de redução, o país também mostrava uma postura contraditória, já que apresentava um Plano Decenal de Energia que propunha dobrar o parque termelétrico do país, 
enfatizando o uso de fontes de energia "sujas", que colaboram com o aquecimento global (Rodas \& Di Giulio, no prelo).

A análise das entrevistas com os jornalistas endossa essas observações. Ainda que a cobertura brasileira sobre mudanças climáticas, em geral, tenha sido reconhecida por um dos jornalistas como "superficial", há apontamentos nas entrevistas que sugerem recente amadurecimento do trabalho realizado pela mídia brasileira ao tratar desses temas.

Eu acho que [a cobertura] não está longe do ideal, não estou dizendo aqui que é a melhor do mundo, mas eu acho que essa mudança está sendo feita. É aquela coisa: a gente saiu do discurso dos "ecochatos" [...] e obviamente a questão ambiental é importante hoje para a qualidade de vida das pessoas, que estão cada vez mais vivendo em cidades, né? (jornalista 1)

[...] depois a impressão é que se começa a agregar informação sobre a economia, sobre o custo que isso teria e para mostrar que valeria a pena reduzir os impactos, investir, gastar dinheiro agora, para gastar menos do que se não fizer nada; você mitigar os impactos ali (jornalista 5)

Esse amadurecimento e a tendência à abordagem de enfrentamento observada tanto passam por mudanças no discurso midiático como refletem também as próprias mudanças vivenciadas na sociedade na qual a mídia está inserida.

[...] obviamente começa muita pressão da sociedade via redes sociais, via blogs, o interesse cresce e obviamente a imprensa acaba cobrindo, e aí, conforme [se] cria essa cultura de cobrir meio ambiente, [se] começa também a ter jornalistas especializados [...] que se debruçam sobre o tema, que entendem e gostam, que começam a perceber as coisas e essas controvérsias no discurso, começam a abraçar a causa, como a gente costuma dizer no popular (jornalista 1).
Hoje em dia, até os próprios especialistas deixam de lado essa coisa de "se a gente não fizer, vai acontecer isso, aquilo, a gente vai ter isso". Hoje, é tentar mesmo minimizar, porque já está dada aí a elevação de pelo menos $2^{\circ} \mathrm{C}$ até o final do século (jornalista 3 ).

Ainda nessa perspectiva, o jornalista 2 argumenta que a discussão sobre mudanças climáticas teria mudado após a divulgação do quarto relatório do IPCC, o qual modificara o foco do problema e a própria discussão na sociedade sobre o fenômeno.

Nesse caso, é a mídia reproduzindo a sociedade [...] $\mathrm{Eu}$ acho que a abordagem mudou porque o foco da discussão mudou. Deixou de ser um problema que era discutido: "Será que é verdade? Será que é o homem que está causando?" e passou para uma certeza de que o problema existe, é real e é o homem que está causando isso e o que vai fazer a respeito. Então, eu acho que a cobertura da mídia está refletindo as mudanças na discussão da sociedade nesses anos (jornalista 2).

[...] houve essa mudança e foi só acompanhando uma transformação que teve na própria fonte, né? (jornalista 5)

É possível pensar ainda que a mudança na abordagem da cobertura midiática pode refletir a série de eventos extremos registrados (nacional e internacionalmente) nos últimos anos e que colocou as mudanças climáticas e a necessidade de estratégias de enfrentamento em evidência nas agendas políticas (Lindoso, 2015) e na mídia.

Quando tem essas grandes tragédias, de chuva, de seca, a mudança climática está aparecendo na discussão, mas aparece de uma forma meio torta, mesmo porque não dá para fazer uma ligação 100\% segura entre mudanças climáticas globais e o que acontece aqui em São Paulo, no Nordeste ou no Rio Grande do Sul. Então, eu acho que é um desafio para a frente (jornalista 1). 
Apesar da dificuldade em mensurar como tais eventos influenciaram e influenciam a opinião pública e a ação política sobre as mudanças climáticas, certamente é possível compreender que "estabelecem uma referência contra a qual governos, antes arredios em debater a mudança climática, não poderiam confrontar de forma leviana" (Lindoso, 2015, s/p).

Moser (2016), ao refletir sobre comunicação e mudanças climáticas, observa que as estratégias comunicativas, em geral, também mudaram ao longo dos anos: de uma preocupação inicial em aumentar a conscientização pública para o problema e explicar a ciência climática para uma comunicação mais focada na divulgação e discussão de possibilidades de ação e estratégias, tendo em vista o empoderamento da audiência para a escolha de opções viáveis de enfrentamento. Assim como os eventos extremos, é possível argumentar que essa nova tendência de comunicação começa a reverberar também na cobertura midiática realizada.

Apesar dessa possível tendência, os jornalistas entrevistados ainda reconhecem deficiências na cobertura nacional, considerada limitada a grandes eventos e acontecimentos e baseada em agências internacionais de notícias ou na mídia internacional, o que, segundo um dos entrevistados, resultaria em um olhar enviesado sobre a temática. Reconhecem também a necessidade de trazer o debate macro sobre questões ambientais, particularmente acerca das mudanças climáticas, para o dia a dia das pessoas. Ao compararem a cobertura midiática feita internacionalmente, os jornalistas entrevistados apontam uma superioridade da cobertura externa, reforçando, inclusive, que ainda é forte a tendência, na mídia brasileira, a reproduzir notícias de agências internacionais e de jornais estrangeiros, algo que havia sido observado também na pesquisa documental sobre as notícias divulgadas no jornal Folha de S. Paulo:
$15,1 \%$ das notícias publicadas nesse periódico no intervalo analisado vieram de mídias internacionais, como BBC, Reuters e Deutsche Welle.

Essa tendência de reprodução de notícias também é explicada pelo jornalista 5 tanto pelo viés da produção científica sobre mudanças climáticas - que para ele seria mais forte internacionalmente - como pela própria dificuldade que os veículos de comunicação têm em manter equipes fora do país.

Na parte de ciência, o Brasil produz uma parcela
pequena da ciência mundial. Deve estar ali por volta
de $2 \%$ a $3 \%$. Os outros $50 \%$ são dos Estados Unidos,
outro bom tanto é a Europa. Então, a origem dessas
informações está fora e isso também chega para os jor-
nalistas brasileiros via agência de notícias ou também
as próprias revistas científicas têm serviços em que
elas mandam pré-releases do que vai sair e alimentam
os jornalistas aqui com isso. Então, a fonte está sem-
pre fora, né? A pessoa nunca está lá acompanhando
o tempo todo, não se tem dinheiro para fazer isso, é
caro para a gente e acho que pouquíssimos jornais
têm correspondentes em vários países (jornalista 5).

Zamith et al. (2012), ao analisarem a mídia latino-americana, destacam que a cobertura midiática nesses países do Sul sobre questões ambientais, em geral, tem sido criticada por ser relativamente superficial, mais centrada nas fontes oficiais do que nos cientistas e por perder a oportunidade de incluir, nos textos divulgados, potenciais soluções ao problema. No caso do estudo realizado com a Folha de S.Pau$l o$, foi possível observar que a maior parte das notícias também privilegiou as fontes governamentais. Da amostra analisada, e considerando seis categorias de fontes estabelecidas - fontes governamentais (presidentes, representantes de governo, ministros, secretários), organizações não governamentais (ONGs), comunidade (moradores, trabalhadores, por exemplo), especialistas (cientistas, biólogos, climatologistas), empresas/empresários e outros 
(quando a classificação em alguma das categorias não foi possível) -, a pesquisa identificou que as fontes governamentais sobressaíram (40,7\%). A segunda fonte mais citada foi a comunidade de especialistas $(33,7 \%)$, seguida das ONGs (como Greenpeace, WWF, Oxfam), com 10\%. A opção por essas fontes pode estar relacionada ao foco das notícias, mais direcionado a decisões políticas e às decisões e disputas travadas nos encontros internacionais nos quais esses temas foram tratados.

Nas entrevistas, essa preferência pelas fontes governamentais é reconhecida, já que a cobertura ainda está mais centrada na política e nas ações e posições dos governos.

A gente ainda está muito no declaratório oficial, a gente ainda tem muito essa ânsia, principalmente em política ou na cobertura de governos, seja ela federal, estadual ou municipal, de dar muita voz para essas fontes oficiais e isso geralmente acontece na mídia internacional também (jornalista 1).

Às vezes, parece que a imprensa privilegia o poder público, mas eu acho que é mais uma questão de falta de tempo e de ouvir outras pessoas. O poder público é geralmente responsável ou tem que tomar uma atitude com reação àquilo que você está noticiando, então é meio que obrigatório você ouvir e aí não sobra tempo de ouvir muitas outras pessoas e parece que você está ouvindo só o governo (jornalista 2).

Contudo, os jornalistas entrevistados mencionam também a necessidade de ouvir especialistas e cientistas para a produção de notícias, na perspectiva de que estes estão produzindo conhecimento científico e têm autoridade e credibilidade para esclarecer os temas tratados.

Há uma preocupação em ouvir fontes de muita credibilidade, então a gente vai sempre procurar esses órgãos que eu te falei, o Inpe, o Cemaden, o
Observatório do Clima [...], que são órgãos que, de certa forma, já criaram um nome no cenário global e consequentemente a gente vai procurar os especialistas que também já são conhecidos da área e envolvidos com esses órgãos (jornalista 5).

A minha cobertura é muito pautada pela ciência, então as minhas principais fontes são sempre a academia, a literatura científica (jornalista 2).

\section{Critérios de noticiabilidade}

Ainda que, ao serem questionados a respeito dos critérios que pesam na hora de divulgar um fato e transformá-lo em notícia, os jornalistas entrevistados tenham apontado que divulgam o que é de interesse da maior quantidade de pessoas, a análise das entrevistas permite identificar três atributos que pesam na cobertura sobre mudanças climáticas: senso de oportunidade, interesse (pelo) humano e conflito. Na literatura, esses atributos podem estar associados a outros termos. Bednarek (2016), por exemplo, ao fazer uma revisão sobre os valores-notícia, chama a atenção para oportunidade (timeliness, referente ao momento em que acontece o fato), negatividade (negativity, incluindo aqui questões de conflito e controvérsia) e impacto (impact, para se referir aos efeitos e consequências de um evento), entre outros atributos.

Sobre senso de oportunidade, os jornalistas entrevistados argumentam que um fato ou uma informação somente vira notícia a partir da divulgação de novos dados de uma pesquisa e de dados relevantes. Nessa perspectiva, os relatórios do IPCC e as novas informações sobre projeções climáticas justificariam um aumento da cobertura midiática. $\mathrm{O}$ interesse (pelo) humano também justifica a produção de notícias, particularmente quando ocorrem desastres e tragédias, como aqueles relacionados à ocorrência de eventos extremos. Se trazem sérios impactos 
a uma determinada comunidade e se apresentam a característica de proximidade geográfica e/ou cultural, ganham ainda maior destaque. Conflitos, tensões e disputas também justificam maior atenção e visibilidade midiática.

Como a gente é um jornal nacional, eu procuro escolher assuntos que sejam do interesse do maior número de pessoas e que tenha relevância no debate político (jornalista 1).

Se a notícia for relevante, se o dado for relevante, a discussão for relevante, ela vai entrar. A escolha é: "Isso é velho? Então, acho que não dá" “Ah, é velho, mas eu acho que dá uma discussão nova. Então vamos colocar de final de semana." "Ah, isso é novo? Então tá, vai para amanhã” (jornalista 5).

Recentemente, na questão da Dilma, a gente teve o tal do pré-sal, que foi vendido como a salvação da lavoura, vai resolver o problema do país, e o pré-sal, obviamente, é uma energia suja. Então, a controvérsia aparece justamente aí [...] Como vai defender o pré-sal se do outro lado tem o discurso de ter uma energia limpa? E ainda tem o desmatamento na Amazônia. Não estou defendendo aqui que não teve esforços para preservar. Teve uma série de leis nesses últimos tempos que foram aprovadas para que a coisa desse uma diminuída, mas o desmatamento da Amazônia tem muito a ver com a questão econômica também. Então, para ser objetivo, existem essas controversas e o jornalismo acaba captando isso com certeza (jornalista 1).

Em geral, histórias que atraem audiências, como dramas pessoais, descobertas extraordinárias, situações que parecem estar fora de controle, conflitos, disputas e desastres, ganham espaço na mídia. Tais histórias, inspiradas no gênero fait divers (Barata, 2006), envolvem fatos diversos sobre escândalos, curiosidades e bizarrices (Dejavite, 2001). Ainda que notícias sobre prevenção, adaptação e mitigação climática não costumem entrar na pauta com a mesma frequência que situações de emergência, justamente por não terem o mesmo apelo de impacto nas vidas humanas (Loose, 2014), as mudanças climáticas, por envolverem controvérsias, riscos e ameaças e por acirrarem disputas, conflitos e tensões entre diferentes atores, atraem a atenção midiática.

Nesse sentido, a análise das notícias veiculadas no período de 2007 a 2009 e que mencionaram o Brasil evidencia confrontos de opiniões e as divergências entre os principais atores dessa arena: fontes governamentais, ONGs, especialistas e empresários. Em 2007, por exemplo, algumas notícias revelavam que dois atores estavam em evidência nesse debate: de um lado, o governo, que não concordava com metas internacionais de GEE para países em desenvolvimento; de outro, as ONGs, que não concordavam com os decretos brasileiros emitidos, consideravam a postura do governo um retrocesso e cobravam objetivos claros do Brasil em face das questões climáticas e energéticas.

O Itamaraty voltou a avisar ontem que o Brasil não aceitará metas internacionais de redução de emissões de gases causadores do aquecimento global para países em desenvolvimento. $\mathrm{O}$ recado foi transmitido pelo subsecretário de assuntos políticos do Ministério das Relações Exteriores [...], às vésperas da $13^{\mathrm{a}}$ Conferência das Partes sobre a Convenção das Nações Unidas sobre o Clima [...] (Folha de S.Paulo, 29/11/2007).

Organizações não governamentais cobraram do Brasil a definição de limites claros de emissões de gases de carbono, embora a maioria tenha evitado criticar de forma direta a resistência do país a que esses limites sejam impostos por acordos internacionais. [...] "É preciso dar um sinal claro de que o país está engajado na diminuição do desmatamento, é preciso ter metas internas. Estamos fazendo a lição de casa? Cadê as nossas metas", disse a analista do WWF Brasil. [...] "O Brasil tem que decidir se quer liderar ou seguir" 
[...], afirmou [...] o diretor de campanhas da ONG [Greenpeace]" (Folha de S. Paulo, 4/12/2007).

Em 2008, a análise dos textos aponta disputas em relação aos biocombustíveis, particularmente no nível internacional, com uma possível reverberação no Brasil, com algumas peças jornalísticas sinalizando seus pontos negativos, como geração de mais poluição e desmatamento.

O presidente Luís (sic) Inácio Lula da Silva entra terça-feira na batalha para evitar que seja satanizado o seu projeto mais ambicioso, o que ele chama de "revolução energética" a partir do etanol [...] diferentes fontes e estudos apontam o álcool combustível como um dos responsáveis pela disparada dos preços (Folha de S. Paulo, 1\%6/2008).

Apesar das crescentes críticas internacionais à produção e uso de biocombustíveis por conta do impacto ambiental e social, o Brasil ainda espera se tornar um grande jogador mundial no setor, segundo reportagem publicada nesta quarta-feira pelo jornal britânico "The Guardian". [...] O "Guardian" afirma que as pesquisas sobre o impacto do álcool de cana-de-açúcar na emissão de gases causadores do efeito estufa são conflitantes, com algumas afirmando que o processo em alguns países emite mais gases do que o economizado com o uso do combustível "limpo" (Folha de S. Paulo, 28/5/2008).

No ano seguinte, para além dos embates entre governo, instituições e ONGs, outros atores ganhavam vozes nas representações midiáticas: especialistas, que cobravam maior atenção ao setor agropecuário, que teria peso na emissão de GEE no país, e evidenciavam o papel das cidades na mitigação das mudanças climáticas; o setor produtivo, com atenção para o fato de que as empresas brasileiras assumiam compromisso de redução de emissão de gases; e a própria sociedade civil, com notícia que indicava que os brasileiros estariam dispostos a pagar mais impostos ou mais caro por energia para amenizar problemas do aquecimento global, apesar de não considerarem esse o problema mundial mais grave.

O peso do setor agropecuário nas emissões de gases de efeito estufa do Brasil é muito mais relevante do que os dados oficiais mostram [...] "O Brasil está mudando seu perfil de emissões. Neste contexto, a pecuária começa a se tornar uma grande vilã", afirma [...] do Cena (Centro de Energia Nuclear na Agricultura), instituição ligada à Universidade de São Paulo (Folha de S.Paulo, 20/10/2009).

Por uma questão puramente econômica, grandes empresas brasileiras anunciaram ontem em São Paulo um compromisso para reduzir suas emissões de gases que contribuem para o aumento do efeito estufa. O documento [...] é assinado por siderúrgicas, empresas de energia, empreiteiras, redes de supermercados, entre outros setores [...] (Folha de S.Paulo, 26/8/2009).

$\mathrm{Na}$ véspera da cúpula do clima das Nações Unidas [...], pesquisa Datafolha revela que a maioria dos brasileiros se diz disposta a pagar mais em impostos ou energia para amenizar efeitos do aquecimento global. Os entrevistados, porém, não consideram as mudanças climáticas o mais grave dos problemas mundiais. Elas aparecem em sétimo lugar, com 5\% (Folha de S.Paulo, 6/12/2009).

A seleção das notícias, como argumenta Sousa (1999), é um processo subjetivo, influenciado pelas experiências, valores e expectativas daqueles que são responsáveis por essa tarefa. $\mathrm{Na}$ construção das notícias, para além desses atributos subjetivos, pesam ainda o espaço, as políticas organizacionais e as características do meio social e da cultura (Guenther \& Ruhrmann, 2016). No nível das influências socioculturais, as notícias transportam consigo os enquadramentos (frames) em que foram produzidas. A escolha de um frame não é inteiramente livre, 
pois depende do catálogo de frames disponíveis em um determinado momento sócio-histórico-cultural; depende ainda das rotinas, do peso das instituições e de outros constrangimentos ao processo jornalístico de produção de informação de atualidade (Sousa, 1999; Guenther \& Ruhrmann, 2016; Engesser \& Brüggemann, 2015).

Sobre essas últimas variáveis, as entrevistas de três jornalistas sugerem que a crise atual do jornalismo tem reflexos diretos na cobertura midiática sobre questões ambientais, incluindo os temas tratados na pesquisa.

A imprensa mais forte tradicionalmente sempre foi a escrita, o jornalismo impresso, os jornais. E, nos últimos anos, teve um enfraquecimento muito grande dos jornais diante da concorrência com a internet. Então, todos os jornais diminuíram de tamanho, demitiram muita gente, as equipes encolheram e isso aumentou a dependência dos veículos em relação às agências internacionais. Então, você não tem um jornalista seu para mandar cobrir uma matéria e pega matéria da agência internacional, e aí você acaba homogeneizando, porque todo mundo usa essas mesmas agências (jornalista 2).

O jornalismo dá a impressão de que é uma profissão que vive em crise, e a circulação dos grandes veículos tem diminuído nos últimos anos, depois que surgiu a internet e a informação mais rápida ali. Os veículos, principalmente os impressos, vêm perdendo circulação (jornalista 5).

No caso específico dos veículos impressos, a redução de circulação e do número de leitores e a queda de participação dos jornais no total do gasto publicitário em meios de comunicação (Righetti, 2016) têm como reflexos diretos o encolhimento das redações e das equipes nos últimos anos e o enfraquecimento dos grandes jornais, consequência também da recente concorrência com a internet.
Com menos espaço, pouco investimento e equipes reduzidas, o jornalismo brasileiro foca mais assuntos que tendem a despertar maior atenção do público, como questões políticas e econômicas e escândalos. A questão ambiental, que historicamente não é tratada como prioridade na mídia (Boykoff \& Yulsman, 2013), tende a perder ainda mais espaço. Contudo, como aponta o jornalista 1 , é possível que a crise também reverbere em uma transformação dos jornais, o que poderia refletir positivamente na cobertura de questões relacionadas ao meio ambiente.

\section{Conclusões}

O estudo realizado confirmou a tendência de uma cobertura midiática sobre mudanças climáticas mais centrada em eventos e acontecimentos pontuais. Dentro do recorte temporal da pesquisa, a análise das notícias publicadas no jornal brasileiro Folha de S. Paulo evidencia dois marcos relevantes e que justificariam o aumento expressivo de peças jornalísticas divulgadas entre 2007 e 2009: a divulgação do quarto relatório do IPCC e a realização da Conferência de Copenhague. Essa tendência, também observada em nível internacional, como sugere a literatura revisada, foi confirmada pelos jornalistas entrevistados, que reconhecem esses momentos como produtores de notícias, os quais resultam em discussões políticas e decisões, possibilitando chamar a atenção do público para a questão ambiental. Esses marcos reúnem os critérios de noticiabilidade que pesam na cobertura midiática, como mostra a análise tanto das notícias como das entrevistas com os jornalistas: apresentam novos dados científicos e informações relevantes (oportunidade), influenciam as tomadas de decisões políticas que vão orientar ações dos governos e dos países (interesse humano) e acirram disputas e tensões entre governos e entre 
governantes/tomadores de decisão e demais atores (conflito).

Ainda que a cobertura realizada pela mídia brasileira siga uma tendência de mudança de enfoque, de uma abordagem de risco para uma abordagem mais atenta às estratégias de enfrentamento e de caráter mais preventivo, com destaque para as conexões entre energia e mudanças climáticas e para uma discussão sobre redução de emissões de GEE e necessidade de energia renovável, refletindo assim as próprias mudanças vivenciadas na sociedade na qual a mídia está inserida, a análise das entrevistas com os jornalistas revela suas percepções acerca das deficiências na cobertura nacional. Entre elas, ganham destaque a própria cobertura centrada em acontecimentos pontuais, a tendência de reprodução de notícias produzidas por agências e mídias internacionais e a dificuldade ainda persistente em trazer o debate macro sobre questões ambientais, particularmente acerca das mudanças climáticas, para o dia a dia das pessoas. Uma das causas para esses entraves, identificada na análise das entrevistas, é a crise atual do jornalismo, que teria reflexos diretos na cobertura midiática.

Reforçamos que, embora o estudo realizado tenha trazido importantes contribuições para o en- tendimento sobre como a mídia brasileira tem divulgado questões associadas às mudanças climáticas, contribuindo para o campo analítico sobre ciência, comunicação e sociedade, há a necessidade de mais pesquisas que enfoquem tanto a cobertura midiática como os impactos dessa cobertura na compreensão pública sobre o fenômeno e na percepção sobre seus riscos. Embora reconheçamos que o público interpreta as notícias de diferentes formas, dependendo de fatores contextuais, como classe, gênero e socialização (Anderson, 1997), e que os efeitos das mensagens dependem de contextos sociais nos quais as notícias são recebidas (Nelkin, 1987), a mídia é, de fato, uma mediadora relativamente poderosa e é um dos agentes que intervêm no processo de construção social da realidade. Por isso mesmo, e reconhecendo a complexidade e o desafio envoltos no tema das mudanças climáticas, ela deve ser objeto de mais estudos compreensivos e analíticos.

\section{Agradecimentos}

As autoras agradecem ao PIBIC-CNPq (150915/ 2015-2) e à Fapesp (2013/17665-5 e 2014/50313-8) pelo suporte à pesquisa realizada e aos comentários dos pareceristas.

\section{Referências}

Aguiar, L.A.; Schaun, A. Heurística do Medo: mídia e meio ambiente na sociedade de risco. Estudos em Comunicação, Sociedade e Cultura, 1(2), 2011. doi: 10.5380/ am.v0i2.26423

Allan, S.; Adam, B. E Carter, C. (Ed.). Environmental risks and the media. London: Routledge, 2000.

Anderson, A. Media, culture and environment. London: UCL Press Limited, 1997.
Anderson, A. Media, Politics and Climate Change: Towards a New Research Agenda. Sociology Compass, 3(2), 166182, 2009. doi: 10.1111/j.1751-9020.2008.00188.x

ANDI - Agência de Notícias dos Direitos da Infância. Mudanças Climáticas na Imprensa Brasileira, 2010. Disponível em: $<$ http://www.andi.org.br/sites/default/files/Mudanca $\% 20$ climatica $\% 20$ na $\% 20$ imprensa $\% 20$ brasilerira $\% 20$ 2005\%202008.pdf>. Acesso em: fev.2017. 
Artaxo Netto, A.P.F. O futuro da Terra: discursos inconvenientes. Campinas, Tese (Doutorado em Linguística) - UNICAMP, 2013.

Baran, M.; Heurich, G.; Sauma, J.; Siqueira, P. “O Clima está Quente, né?": justaposições e distanciamentos entre público e especialistas brasileiros sobre as mudanças climáticas. Relatório de Pesquisa. Instituto Frameworks, 2015. Disponível em: <http://arapyau.org.br/comofalarsobreclima/wp-content/uploads/2015/11/Relatorio-FrameWorks-Final.pdf>. Acesso em: fev.2017.

Barata, G. F. A primeira década da Aids no Brasil: o Fantástico apresenta a doença ao público (1983-1992). São Paulo, Dissertação (Mestrado em História) - USP, 2006.

Barkemeyer, R.; Figge, F.; Hoepner, A. Holt, D.; Kraak, J.M. Media coverage of climate change: An international comparison. Environment and Planning C: Politics and Space, 0(0), 1-26, 2017. doi: 10.1177/0263774X16680818

Beck, U. Sociedade de risco rumo a uma outra modernidade. Tradução de Sebastião Nascimento. 2. ed. São Paulo: Editora 34, 2011.

Bednarek, M. Voices and values in the news: News media talk, new values and attribution. Discourse, Context and Media, 11, 27-37, 2016. doi: 10.1016/j.dcm.2015.11.004

Bonanno, L. P. Os bastidores do jornalismo científico: critérios de noticiabilidade que determinam a circulação da informação à sociedade. São Paulo, Dissertação (Mestrado em Ciências) - USP, 2015.

Boykoff, M.; Yulsman, T. Political economy, media and climate change: sinews of modern life. WIREs Clim Change, 4(5), 359-371, 2013. doi: 10.1002/wcc.233

Brüggemann, M.; Engesser, S. Between consensus and denial: Climate journalists as interpretive community. Science Communication, 36(4), 399-427, 2014. doi: 10.1177/1075547014533662

Bueno, W. C. O jornalismo ambiental circula na arena da ciência e da política. Anuário Unesco/Metodista de Comunicação Regional, 13(13), 113-126, 2009. doi: 10.15603/2176-0934/aum.v13n13p113-126

Carvalho, A. Ideological cultures and media discourses on scientific knowledge: re-reading news on climate change. Public Understanding of Science, 16, 223-243, 2007. doi: $10.1177 / 0963662506066775$
Carvalho, A. Media (ted) discourses and climate change: a focus on political subjectivity and (dis) engagement. Wiley Interdisciplinary Reviews: Climate Change, 1, 172-179, 2010. doi: 10.1002/wcc.13

Carvalho, A.; Burgess, J. Cultural Circuits of Climate Change in U.K. Broadsheet Newspapers, 1985-2003. Risk Analysis, 25(6), 1457-1469, 2005. doi: 10.1111/j.15396924.2005.00692.x

Climate and Development Knowledge Network. Gerenciando extremos climáticos e desastres na América Latina e no Caribe: Lições do relatório SREX IPCC. 2012. Disponível em: $<$ http://www.fapesp.br/ipccsrex/upload/SEX-Lessons-Portuguese-LAC.pdf $>$. Acesso em: dez. 2012.

Darela-Filho, J. P.; Lapola, D. M.; Torres, R. R.; Lemos, M. C. Socio-climatic hotspots in Brazil: how do changes driven by the new set of IPCC climatic projections affect their relevance for policy? Climatic Change, 136 (3), 413425, 2016. doi: 10.1007/s10584-016-1635-Z

Dejavite, F. A. O poder do fait divers no jornalismo: humor, espetáculo e emoção. In: Anais do XXIV Congresso Brasileiro de Ciências da Comunicação. Campo Grande, $3-7$ de set., 2001.

Denton, F.; Wilbanks, T. J.; Abeysinghe, A. C.; Burton, I.; Gao, Q.; Lemos, M. C.; Masui, T.; O’brien, K. O.; Warner, $\mathrm{K}$. Climate-resilient pathways: adaptation, mitigation, and sustainable development. In: Climate Change. 2014: Impacts, Adaptation, and Vulnerability. Part A: Global and Sectorial Aspects. Contribution of Working Group II to the Fifth Assessment Report of the Intergovernmental Panel on Climate Change. 2014. p. 1101-1131.

Di Giulio, G. M. Risco, ambiente e saúde: um debate sobre comunicação e governança do risco em áreas contaminadas. São Paulo: Annablume/Fapesp, 2012.

Di Giulio, G. M.; Pereira, N. M.; Figueiredo, B. R. O papel da mídia na construção social do risco: o caso Adrianópolis, no Vale do Ribeira. História, Ciências, Saúde-Manguinhos, 15(2), 293-211, 2008. doi: /10.1590/ S0104-59702008000200004

Di Giulio, G. M.; Vasconcellos, M. P.; Günther, W. M. R.; Ribeiro, H.; Assunção, J. V. Percepção de risco: um campo de interesse para a interface ambiente, saúde e sustentabilidade. Saúde e Sociedade, 24(4), 1217-1231, 2015. doi: 10.1590/S0104-12902015136010 
Di Giulio, G. M. et al. Plano Nacional de Adaptação à Mudança do Clima: possibilidades e desafios. Jornal da Ciência, 5520, 2016. Disponível em: <http://www.jornaldaciencia.org.br/edicoes/?url=http://jcnoticias.jornaldaciencia.org.br/24-plano-nacional-de-adaptacao-a-mudanca-do-clima-possibilidades-e-desafios/>. Acesso em: out. 2016.

Di Giulio, G. M.; Bedran-Martins, A. M.; Lemos, M. C. Adaptação climática: fronteiras do conhecimento para pensar o contexto brasileiro. Estudos Avançados, 30(88), 25-41, 2016. doi: $10.1590 / \mathrm{s} 0103-40142016.30880004$

Duarte, R. Entrevistas em pesquisa qualitativas. Educar em Revista, 24, 213-225, 2004. doi: 10.1590/0104-4060.357

Engesser, S.; Brüggemann, M. Mapping the minds of the mediators: The cognitive frames of climate journalists from five countries. Public Understanding of Science, 25(7), 825841, 2016. doi: 10.1177/0963662515583621.

Flynn, J.; Slovic, P.; Kunreuther, H. Media and stigma: understanding public challenges to modern science and technology. London: Earthscan, 2001.

Ford, J. D.; King, D. Coverage and framing of climate change adaptation in the media: A review of influential North American newspapers during 1993-2013. Environmental Science and Policy, 48, 137-146, 2015. doi: 10.1016/j.envsci.2014.12.003

Giddens, A. Risk and Responsibility. The Modern Law Review Limited. 62(1), 1-10, 1999. doi: 10.1111/14682230.00188

Giesbrecht, M. D.; Di Giulio, G. M.; Ferreira, L. C. Brasil e a questão energética no debate sobre mudanças ambientais globais. In: De Castro, F.; Futemma, C. (Orgs.). Governança ambiental no Brasil: entre o socioambientalismo e a Economia Verde. Jundiaí: Paco Editorial, 2015. p. 239-260.

Guenther, L.; Ruhrmann, G. Scientific evidence and mass media: Investigating the journalistic intention to represent scientific uncertainty. Public Understanding of Science, 25(8), 927-943, 2016. doi: 10.1177/0963662515625479

Hannigan, J. Environmental Sociology. 2. ed. Petrópolis: Vozes, 2006.

Hansen, A. Claims making and framing in British newspaper coverage of the -Brent Spar\| controversy. In: Allan, S.; Adam, B.; Carter, C. (Orgs.). Environmental risks and the media. London: Routledge, 2000. p. 55-72.
Happer, C.; Philo, G. New approaches to understanding the role of the news media in the formation of public attitudes and behaviours on climate change. European Journal of Communication, 31, 136-151, 2015. doi: 10.1177/ 0267323115612213

IPCC - Painel Intergovernamental sobre Mudanças do Clima. Mudança do Clima 2007: mitigação da mudança do clima. $4^{\circ}$ relatório de avaliação do IPCC. Disponível em: <http://www.ipcc.ch/report/ar4/>, Acesso jan. 2015.

IPCC - 'Summary for policymakers'. In: Climate Change 2013: The Physical Science Basis. Contribution of Working Group I to the Fifth Assessment Report of the Intergovernmental Panel on Climate Change. Edited by: T.F. Stocker, D. Qin, G.-K. Plattner, M. Tignor, S.K. Allen, J. Boschung, A. Nauels, Y. Xia, V. Bex and P.M. Midgley. Cambridge: Cambridge University Press. 2013.

IPEA - Instituto de Pesquisa Econômica Aplicada. Climate change in Brazil: economic, social and regulatory aspects. 2011. Disponível em: <http://www.ipea.gov.br/agencia/ images/stories/PDFs/livros/livros/livro_climatechange. pdf>, Acesso em: out. 2015.

Itamaraty. Pretendida contribuição nacionalmente determinada para consecução do objetivo da Convenção-Quadro das Nações Unidas sobre Mudança do Clima. 2015. Disponível em: $<$ http://www.itamaraty.gov.br/images/ed_desenvsust/BRASIL-iNDC-portugues.pdf>. Acesso em: nov. 2015.

Kasperson, R. et al. The social amplification of risk: a conceptual framework. In: Kasperson, J.; Kasperson, R. The social contours of risk: publics, risk communication and the social amplification of risk. London: Earthscan, 2005. p. 99-114.

Leite, J. C. Controvérsias na climatologia: o IPCC e o aquecimento global antropogênico. Scientice Studia, São Paulo, 13(3), 643-677, 2015.

Lindoso, D. P. Adaptação à mudança climática: ciência, política e desenvolvimento sustentável. ClimaCom Cultura Cientifica - pesquisa, jornalismo e arte, 2(2), 2015. Disponível em: < http://climacom.mudancasclimaticas. net/?p=1967>. Acesso: em ago. 2015.

Loose, E. B. Comunicação de riscos e Jornalismo: considerações sobre esta relação a partir das mudanças do clima. In: Anais do III Congresso Internacional, I Simpósio Ibero-Americano, VIII Encontro Nacional de Riscos Coimbra: Portugal, 2014. doi: 10.14195/978-989-96253-3-4_2 
Loose, E. B.; Carvalho, A. O que pensam os jornalistas sobre seu papel no enfrentamento das mudanças climáticas: as percepções dos profissionais da Gazeta do Povo no Paraná, Brasil. Razón y Palabra, 91, 33-57, 2015. Disponível em: <www.revistarazonypalabra.org/index.php/ryp/article/ download/74/132>.

Lowe, T.; Brown, K.; Dessai, S.; Doria, M.F; Haynes, K.; Vincent, K. Does tomorrow ever come? Disaster narrative and public perceptions of climate change. $P u b$ lic Understanding of Science, 15, 435-457, 2006. doi: 10.1177/0963662506063796

Marengo, J. A. A seca e a crise hídrica de 2014-2015 em São Paulo. Revista USP 106, 31-44, 2015. Disponível em: $<$ https://www.usp.br/revistausp/106/3\%20marengo.pdf $>$.

McCombs, M. E. Setting the Agenda: The Mass Media and Public Opinion. Cambridge: Polity Press, 2004.

McComas, K.; Shanahan, J. Telling stories about global climate change: measuring the impact of narratives on issue cycles. Communication Research, 26(1), 30-57, 1999. Disponível em: < http://journals.sagepub.com/doi/pdf/10.1177 /009365099026001003>. Acesso em: out.2016.

McCombs, M. E.; Shaw, D. L. The agenda-setting function of mass media. Public Opinion Quartely, 36(2), 176-187, 2012. Disponível em: $<$ https://www.unc.edu/ fbaum/teaching/PLSC541_Fall06/McCombs\%20and\%20Shaw\%20 POQ\%201972.pdf>. Acesso em: out.2016.

Miller, M. M.; Riechert, B. P. Interest group strategies and journalistic norms - News media framing of environmental issues. In: Allan, S.; Adam, B.; Carter, C. (Orgs.). Environmental risks and the media. London: Routledge, 2000. p. 45-54.

Moreira, H. M. A formação da geopolítica das mudanças climáticas. Sustentabilidade em Debate, 4, 275-292, 2013. doi: 10.18472/SustDeb.v4n1.2013.9211

Moser, S. C. Communicating adaptation to climate change: the art and science of public engagement when climate change comes here. WIRES Clim. Change, 5, 337-358, 2014. doi: 10.1002/wcc. 276

Moser, S.C. Reflections on climate change communication research and practice in the second decade of the $21^{\text {st }}$ century: what more is there to say? WIRES Clim. Change, 7 , 345-369, 2016. doi: 10.1002/wcc.403
Nelkin, D. Selling Science: How the press covers science and technology. New York: W. H. Freeman and Company, 1987.

Nobre, C. et al. Vulnerabilidades das megacidades brasileiras às mudanças climáticas: Região Metropolitana de São Paulo, 2010. Disponível em: <http://www.issonaoenormal. com.br/CLIMA_SP_FINAL.pdf $>$. Acesso em: jul. 2013.

O’Neill, S.; Nicholson-Cole, S. "Fear Won't Do It" - Promoting Positive Engagement With Climate Change Through Visual and Iconic Representations. Science Communication, 30(3), 355-379, 2009. doi: 10.1177/1075547008329201

PBMC. Contribuição do Grupo de Trabalho 1 ao Primeiro Relatório de Avaliação Nacional do Painel Brasileiro de Mudanças Climáticas. Sumário Executivo GT1. PBMC, Rio de Janeiro, Brasil, 2013. Disponível em: <http://www.pbmc. coppe.ufrj.br/documentos/RAN1_completo_vol1.pdf $>$.

Pidgeon, N.; Kasperson, R.E.; Slovic, P. The Social Amplification of Risk. Cambridge: Cambridge University Press, 2003.

Righetti, S. Novo jornalista tem de ir muito além de escrever uma reportagem. ComCiência. 2016. Disponível em: $<$ http://www.comciencia.br/comciencia/?section=8\&edi$\mathrm{cao}=122 \& \mathrm{id}=1478>$. Acesso em: out.2016.

Rodas, C. A.; Di Giulio, G. M. Mudanças climáticas na mídia brasileira: reflexões sobre a cobertura jornalística. In: Di Giulio, G.; Monteiro, M. (Orgs.). Comunicação, política e representação: interfaces com ciência, tecnologia e ambiente. No prelo.

Shanahan, J.; McComas, K. Telling Stories about climate change. Communication Research, 26(1), 30-57, 1999. Disponível em: <http://journals.sagepub.com/doi/pdf/10.1 177/009365099026001003>.

Sousa, J. P. As noticias e os seus efeitos: as "teorias" do jornalismo e dos efeitos sociais dos media jornalísticos. Porto, Portugal: Universidade Fernando Pessôa, 1999.

Stern, N. The economics of climate change. Cambridge, UK: Cambridge University Press, 2006.

Stern, N. Growth, climate and collaboration: towards agreement in Paris 2015. Policy Paper, 2014. Disponível em: <http://eprints.1se.ac.uk/64538/1/Growth_Climate_ and_Collaboration_Stern_2014.pdf $>$.Acesso em: out. 2016. 
Sturloni, G. Le mele de Chernobyl sono buone: mezo secolo di rischio tecnológico. Milano: Editore Sironi, Italy. 2006.

Szerszynski, B.; Toogood, M. Global citizenship, the environment and the media. In: Allan, S.; Adam, B.; Carter, C. (Orgs.). Environmental risks and the media. London: Routledge, 2000. p. 218-228.
Weber, E.; Stern, P. Public Understanding of Climate Change in the United States. American Psychological Association, 66(4), 315-328, 2011. doi: 10.1037/a0023253

Zamith, R.; Pinto, J.; Villar, M. E. Constructing climate change in the Americas: An analysis of news coverage in U.S. and South American Newspapers. Science Communication, 35, 334-357, 2012. doi: 10.1177/1075547012457470 